\title{
Pro-and Anti-vaccination among Mothers in Deciding Children's Immunization: A Qualitative Study
}

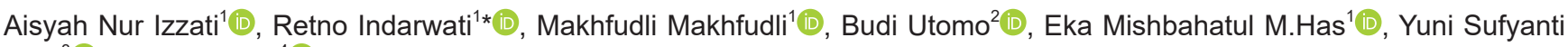 \\ Arief $^{3}$ (D) Hidayat Arifin ${ }^{4}$ (D) \\ ${ }^{1}$ Department of Advanced Nursing, Faculty of Nursing, Universitas Airlangga, Surabaya, Indonesia; ${ }^{2}$ Department of Public Health \\ Sciences - Preventive Medicine, Faculty of Medicine Universitas Airlangga, Surabaya, Indonesia; ${ }^{3}$ Department of Fundamental \\ Nursing, Faculty of Nursing, Universitas Airlangga, Surabaya, Indonesia; ${ }^{4}$ Department of Medical-Surgical Nursing, Faculty of \\ Nursing, Universitas Padjadjaran, Bandung, Indonesia
}

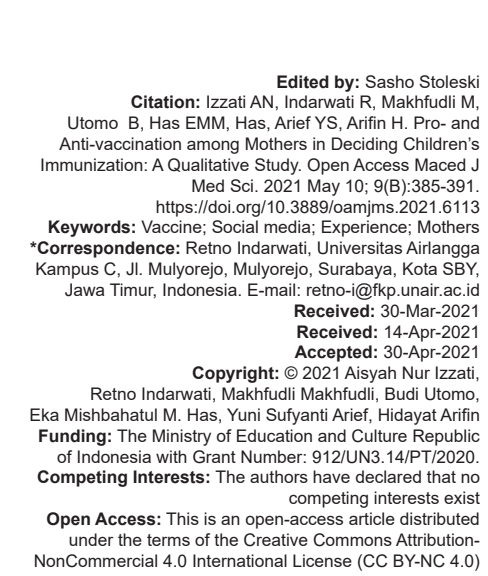

Introduction

To the present time, immunization is considered to be one of the efforts that are the most cost-effective in reducing the number of children with disabilities and mortalities due to infectious diseases because it can provide health protection for the community in a population [1]. Immunization is also one of the government's priority programs to achieve one of the targets in the Sustainable Development Goals. The target achievement set in 2019 was that $93 \%$ of children aged $0-11$ months in Indonesia were administered complete basic immunization [2]. In Indonesia, immunization is influenced by many factors such as age, knowledge, residence, wealth quintiles, and current visit health vacility [3], [4]. Every government must have a system and policies to access the basic immunization program by all people.

However, there are many challenges because there are many parents dating those who do not want to immunize their children who claim to be anti-vaccines. The basic immunization program has recently become a hot topic for debate in cyberspace and the real world by the pro-vaccine and the anti-vaccine communities. The anti-vaccine parental viewpoints and arguments that are widespread on social media seem to be more exciting, and they are also firm to argue based on journal articles [5]. According to the WHO (2017), the vocal antivaccine community not only refuses immunization for themselves/their children, but they also try to prevent other people from receiving immunizati]]. In addition, data in Indonesia found that society participation in the provision of mandatory vaccines for children aged 12-23 months decreased from $59.2 \%$ in 2013 to $57.9 \%$ in 2018 [7].

Constructive strategies are required to overcome the problem of doubt and immunization refusal in parents, so it is crucial to understand the anti-vaccine parents's perspective [8]. Anti-vaccine parents' viewpoints and perspectives do not seem to be understood by every health professional because it is considered complicated [9]. The reasons that motivated the parents' decision to refuse immunization are very complex and varied. Unquestionably, this situation requires special attention. In this case, nurses 
have an important role in increasing knowledge to mothers about the importance of vaccines in children. Approaches through good communication need to be made between nurses and parents.

Therefore, this study was conducted to add to the limited literature in Indonesia. This study explored the perspectives, backgrounds, reasons, and understanding of anti-vaccine and pro-vaccine parents in considering basic immunization decisions to their children to fill the literature gap and provide new insights to health professionals regarding the immunization refusal polemic in parents.

\section{Methods}

\section{The research team and reflexivity}

In-depth interviews were conducted directly by the researcher. The head researcher has an educational background as a community nurse and researcher. The research teams were male and female who had received training and experience in qualitative research and publications. There was no relationship between the researcher and the participant. Participants know well the objectives and topics of the research being carried out.

\section{Study design}

This study used a phenomenology qualitative design that allowed researchers to conduct in-depth interviews with participants. This study's phenomenon was the mother's confidence about the administration of mandatory basic immunization, also the background that led the mothers to decide to become anti-vaccine or pro-vaccine communities.

\section{Sample and settings}

This study involved mothers who were members of the anti-vaccine and pro-vaccine communities on social media of Facebook, with a total of 10 participants who were selected using an area sampling technique. The participants were selected from rural and urban areas to determine their experiences on immunization decisions from various areas. A number of 5 participants were from antivaccine members' community and 5 other participants were from pro-vaccine members' community to represent the different perspectives and experiences of the two parties. There were no specific criteria in selecting the sample considering the topic discussed was quite controversial. Hence, the researcher conducted in-depth interviews with mothers who were willing to become participants.

\section{Data collection}

The interviews were conducted from June to August 2020 by visiting participants' homes. The interviews took place in a room for only the participant and researcher to maintain the participant's privacy so that the researcher could obtain rich data. In this study, we used methodological and researcher triangulation, which uses various methods to study a single problem. Researcher triangulation provided more information based on other points of view. The data collection used in-depth structured interviews, in which the same questions were asked to each participant with additional probes to discuss topics raised by participants themselves. The main questions consist of vaccination "Can you explain or describe about vaccination based on your perception?", social media "Can you explain about your perception and attitude towards vaccine news on social media?", religion "How is the view of the religion or belief regarding the giving of immunization?", barriers "Can you explained the barriers towards vaccinations?", and government's role "How is the government's policies about vaccination?". The instruments used in the qualitative data collection consisted of interview guidelines adapted from the WHO SAGE Working Group on Vaccine Hesitancy Question [10]. The interviews lasted 30-45 $\mathrm{min}$ and were recorded using a voice recorder, transcribed word by word. In exploring the research data, the researcher used the bracketing concept, which was by ignoring all personal assumptions related to the phenomenon of the study. Next, the transcript and analysis were returned to the participants for corrections related to the suitability of the data and the results obtained. Each participant's audio recording was given a unique code label, and then the transcript of the conversation was stored on the researcher's laptop which was secured by a password so that the researcher can only access it.

\section{Data analysis}

The results of the study were analyzed using the thematic analysis method. After conducting interviews with the participants, the researcher transcribed the audio recordings and analyzed them by encoding and categorizing the participants' experiences, feelings, and perspectives. We found 40 categories and 50 codes on the initial stage and became 30 categories and 42 codes on final results after. This study's themes were formulated based on a thematic analysis of participants' answers and field notes. The themes were obtained by repeatedly reading the entire participant description narratives, then quoting meaningful statements, and describing the meaning in these significant statements through keywords. The keywords' essence and meaning were then organized by collecting meaningful statements in similar categories in the themes and subthemes [11]. 


\section{Ethical consideration}

This study has received research ethics approval from the Ethics Committee with number 1837 KEPK. All the ethical issues of qualitative studies were considered. Before the data collection through in-depthinterview, the researchers explained the study purpose and confidentiality of the information was explained to the participants and written informed consent was obtained. In this study, the participants had the right to withdraw from the study at any time.

\section{Results}

The respondents in this study were mothers who were members of the pro-vaccineanti-vaccinecommunities on social media of Facebook. There were 10 participants in this study; the ages of the participants ranged from 24 to 37 years. The participants' residence varied from urban to rural areas. The participants' occupation also varied, such as housewife, teacher, grocery store traders, online seller, and worker in a laundry service (Table 1).

Table 1: Characteristics of the participants $(n=10)$

\begin{tabular}{llllll}
\hline Code & Community & Age & Number of children & Residence & Occupation \\
\hline P1 & Anti-vaccine & 28 & 3 & Rural & Grocery store trader \\
P2 & Anti-vaccine & 32 & 2 & Rural & Online seller \\
P3 & Anti-vaccine & 30 & 3 & Rural & Laundry service \\
P4 & Anti-vaccine & 37 & 1 & Urban & Herbal product seller \\
P5 & Anti-vaccine & 34 & 2 & Rural & Teacher \\
P6 & Pro-vaccine & 30 & 1 & Urban & Online seller \\
P7 & Pro-vaccine & 27 & 1 & Urban & Housewife \\
P8 & Pro-vaccine & 29 & 2 & Rural & Online seller \\
P9 & Pro-vaccine & 25 & 1 & Rural & Grocery store trader \\
P10 & Pro-vaccine & 24 & 1 & Rural & Housewife \\
\hline
\end{tabular}

Based on the data collected, there were four themes obtained, including social media values, perceptions of immunization, immunization barriers, and knowledge about immunization. Each of these themes has a category that will be explained individually to represent the overall results of the participants' interview results (Figure 1).

\section{Social media values}

The theme of social media values described the participants' responses and assessments in receiving news about immunization currently circulating on social media.

\section{Impact of negative news}

The anti-vaccine participants were very aware of negative news on social media regarding basic immunization. Stories about the negative impact after administering basic immunization made them feel pity and empathy for the victims and raise their concerns about vaccine safety. This is one of the reasons for them to believe that not all vaccine administration is successful.

"About the negative impacts, for example, I heard that there was someone who died after receiving the vaccine, that makes me worried, and there is also another case, Miss, that my brother in Jombang (rural area) is disabled for a lifetime after receiving polio immunization" (P4) In contrast to the anti-vaccine participants, the pro-vaccine participants thought that much negative news on social media was a hoax.

"So far, I think immunization is positive, so if I read such negative news, I think maybe there is something missing in the immunization, maybe the baby is sick or something else." (P8)

\section{Impact of positive news}

The pro-vaccine participants were very excited when they read news about the success of

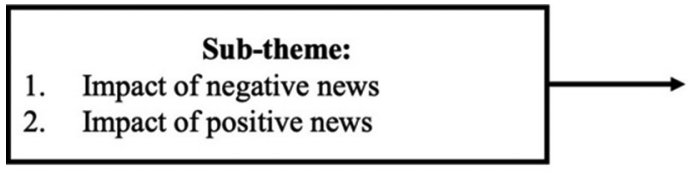

\begin{tabular}{|l|}
\hline \multicolumn{1}{|c|}{ Sub-theme: } \\
1.
\end{tabular}

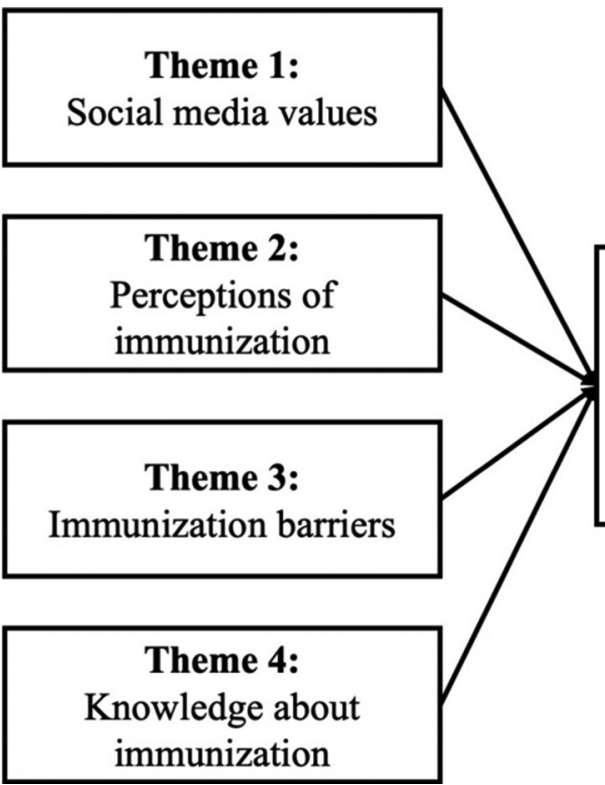

Pro- and AntiVaccination among mothers in Deciding Sub-theme:

1. Time of immunization

2. Availability of vaccine stocks

3. Attitudes of health workers Children's Immunization

\section{Sub-theme:}

1. The purpose of immunization

2. Immunization substitutes
Knowledge about immunization

Figure 1: Themes and sub-themes distributions 
immunization. The pro-vaccine participants feel secure and increase their confidence in the safety of basic immunization.

"I think, when I read the positive news on social media, it gives the positive benefits, so I become more confident about immunization" (P10)

\section{Perceptions of immunization}

In this theme, contrasting perceptions were obtained between the anti-vaccine and pro-vaccine participants, both in terms of religion, confidence about vaccine safety, and their views on government policies.

\section{The religious side}

The anti-vaccine participants considered that administering the vaccine in immunization was still in doubt for its halal status because a vaccine composition was made from pigs. One participant also thought that administering immunization to children was the same as adding disease.

"Because the vaccine administered is still doubtful whether it is halal or haram, halal or not, of course, I don't want to put something in my child, Miss, that is doubtful for the halal status" (P2)

The pro-vaccine participants considered vaccination to be an effort to improve immunity and the health of their children so that it was considered permitted.

"According to Indonesian Religious Leader, the legal category is permitted, according to Ibarul Ulama, it is also permitted, because it is an emergency, there is no substitute. and some vaccines are also halal, no halal label does not mean that it is haram, Miss" (P6)

\section{Vaccine quality}

The biggest question for them was the emergence of adverse events following immunization (AEFI) while the vaccine quality is guaranteed safe.

"I don't know, hehehe (laugh), I haven't immunized my children for a long time, so I don't know. but just in case, I don't administer the vaccine, that's because I'm worried about the AEFl" (P3)

On the other hand, the pro-vaccine participants believed that the vaccine quality was guaranteed safe even though they knew that some children suffered from AEFI.

"Seen from my child, I don't see any side effects or fake ones or something else. but from the information on Facebook, there are some that have paralyzing effects, but I still believe that the quality is safe" (P10)

\section{Views on the government}

The anti-vaccine participants thought that a big business behind the government's policy required basic immunization. According to them, every parent had the right to choose whether or not to give basic immunizations to their children. The policy on mandatory basic immunization was not wise.

"For immunization, every citizen has the right to refuse, because there are other alternatives. if that is the only one available, okay then the government can make it mandatory, but for now, there are other alternatives, such as herbal products, or from the religious perspective" (P4)

On the other hand, the pro-vaccine participants strongly supported the government's policy to make it mandatory basic immunization for every child to improve the health of the Indonesian people.

\section{"If the government make it mandatory, I think it's good, because it is for the health of Indonesian children in the future. considering that there are many strange diseases now" (P10)}

\section{Immunization barriers}

In this theme, it obtained that almost all antivaccine participants considered that all the barriers they faced in administering immunization were not a reason for themselves not administering immunizations. The pro-vaccine participants experienced many barriers in administering immunization and expected that the system would be refined to have no more barriers regarding immunization.

\section{Time of immunization}

The pro-vaccine participants who were housewives or worked at home did not have a problem queuing when immunization was administered. In contrast, the participants who worked outside of home thought it was very time-consuming.

"For me, it's because I have to wait too long... it was complicated. because I had to queue, what do you call it, besides it was complicated, the midwife was not too focused on the vaccine that was scheduled that day, while I had to work" (P5)

\section{Availability of vaccine stocks}

All pro-vaccine participants complained that they had run out of vaccine stocks which made them 
return for the next schedule. The majority of participants reported that the inactivated polio vaccine (IPV) vaccine stocks ran out in many regions.

"In that group, it is reported that the IPV ran out everywhere, I have been waiting for it from last month. two weeks ago, I am asked to come back to the health services, but it turned out that it was not available" (P9)

\section{The attitude of health workers}

Some pro-vaccine participants complained about the health workers' attitude that tended to be ignorant when administering vaccines to their children.

"I think her attitude was unethical one time, when she wanted to inject it in the. she still talked to her friend. I was afraid she didn't pay attention or there would be something wrong with the injection" (P7)

It is quite interesting that one of the anti-vaccine participants shared her experience during childbirth in which the health worker advised her not to administer immunization for her child. This made her sure not to administer basic immunizations to her child until now.

"The midwife asked, 'Well, immunization is like giving the disease, if the body is immune; it means the child is healthy, if the child is sick, it means the body is not fit.' That's why I am confident not to administer an immunization. That makes me confident about it" (P1)

\section{Knowledge about immunization}

It obtained that both anti-vaccine and provaccine participants had fairly good knowledge about immunization. However, the difference was that the anti-vaccine participants believed various other ways that could be carried out to increase children's immunity apart from immunization.

\section{The purpose of immunization}

The majority of the anti-vaccine participants knew that immunization was a way to increase children's immunity, but some participants understood that administering immunization was the same as adding disease to children.

"Immunization is for protection against disease, right, based on what I know so far, the virus is inserted to the body, the virus has been in the killed form, or it is weakened" (P3)

\section{Immunization substitutes}

The majority of the anti-vaccine participants believed that the herbal medicines could replace immunization, exclusive breastfeeding, other strategies (putting a bit of honey on the baby's palate), and letting children play in the environment.

"Well, it increases the immunity system, consumption of herbal products; there are a lot of herbal products anyway. I think there are many products to increase the immune system, like gamat jelly, honey, propolis, black cumin" (P4)

Meanwhile, according to the pro-vaccine participants, immunization was the only best way to increase the immune system and protect children's health so that other methods could not repalce it.

"So far, there are no other ways, well, immunization is the only way to prevent disease until now" (P7)

\section{Discussion}

This study explored the reasons for antivaccine and pro-vaccine mothers in considering their decision to administer immunization for their children from various contexts and from the previous literature that mostly only focused on one context. The results of in-depth interviews in this study showed that the anti- and pro-vaccine participants made social media their source of immunization information. The provaccine participants referred to the "Immunization conscious movement" group on Facebook, Indonesian Pediatrician bond, and the official doctor's account as their reference for immunization. In contrast, the antivaccine participants referred to the Facebook groups, articles, and YouTube. The pro-vaccine participants responded more to positive news about immunization because it made them feel calm and confident. They considered negative news about immunization was only a hoax. The anti-vaccine participants were more concerned with negative news because they thought it made them feel empathetic, and it could be used as lessons to be more careful, and they could anticipate the side effects of immunization.

The public had actually discussed rumors about vaccines before social media existed, but the existence of social media at this time makes negative rumors about vaccines spread very quickly and widely [12]. Social media is considered to have a higher effect and potential to change a person's assumption and behavior than a website. The dependence of the community on social media for accessing information will continue to increase and will increasingly influence their personal decision-making process regarding health [13], policymakers and health workers should consider this phenomenon to participate in discussing immunization issues with the community to bridge the information gap regarding basic immunization. 
The controversy over hesitancy and refusal of immunization is often illustrated as a problem affecting the predominantly Muslim community. However, this study proved that religious factors were not a factor that could affect an individual's immunization hesitancy status. All the anti-vaccine and pro-vaccine participants were religious, but both had different views and confidence regarding basic immunization. The participants from the anti-vaccine community had hesitancy about the halal status of the vaccine, in which it was a strong reason for them not to immunize their children. In contrast, the pro-vaccine community member thought that the vaccination law was permitted because it is an emergency that there is no cure for the diseases until now so that basic immunization was considered to be a form of an effort to maintain the health of their children. In general, all religions state that every individual has the right to decide whether or not to give immunization to their child based on their conscience and belief [14]. This can have an impact on the behavior of mothers in giving vaccines to their children.

This study also showed that the anti-vaccine parents admitted that the concern about vaccine side effects was one of the aspects that made them hesitant about basic immunization. They questioned the safety of the vaccine given, if the vaccines were guaranteed, it is questionable why there were still several incidents of fatal side effects ranging from disability to death. That reason led them to decide not to administer basic immunizations because they did not want their child to be one of these unlucky children. The previous study showed that mothers' attitudes toward immunization had a significant effect on their intention to join the basic immunization program [15]. Building parental vaccine confidence is more complicated than changing an individual's thoughts. Understanding parental confidence in receiving immunizations is critical to any basic immunization program [16]. Parents who refuse immunization do not need a statement that "all vaccines are safe and effective." They only want health workers to explain the facts about vaccines' true and effectiveness without any intimidation [17]. Thereby, honest and positive communication and mutual trust between parents and health services are the most powerful factors in increasing parental acceptance of basic immunization.

Parental vaccine hesitancy is also due to the consideration that immunization programs are one of the major businesses of pharmaceutical companies [18]. Most anti-vaccine participants thought that the basic immunization program was mandatory by the government because it was motivated by mutually beneficial business motives between the government and pharmaceutical manufacturers that produce the vaccines. They deeply regretted the government's policy which required basic immunization to every child, in which they thought that it is the right of every parent to make the best decisions for their children.
One of the barriers perceived by some antivaccine and pro-vaccine participants was queuing to receive immunizations which take time, especially for working mothers. The previous study showed that waiting time in all health facilities was a barrier for parents to provide immunizations [19]. Another barrier perceived by almost all anti-vaccine and pro-vaccine participants was related to the availability of vaccine stocks in their surrounding areas, resulting in unorganized vaccine schedules. The lack of vaccine stocks and the poorly organized schedule of vaccines in health services were one of the reasons for parent's vaccine hesitancy [20], [21].

The anti-vaccine and pro-vaccine parents both had quite good knowledge about immunization. The difference was that the anti-vaccine parents had the confidence to select other natural alternatives to increase their child's immune system. Most antivaccine communities preferred the natural way to provide immunity to their children rather than immunization [22]. They did not see vaccine-preventable diseases as a threat but as an attempt by the body to acquire natural immunity. One of the anti-vaccine participants believed that administering immunization was the same as adding disease to her child's body. She added that she got the insight from a health worker around her area. Knowledge and attitudes of health workers regarding immunization affect the decision in giving immunization by parents [23]. Therefore, the health workers need to have the knowledge and a good attitude toward immunization because they are the most trusted people by the community in making decisions about immunization [24].

The limitation in this study is that all participants were Muslim so that demographic characteristics, particularly in terms of religion, were considered less diverse. This study could not obtain the views of basic immunization from other religions. In addition, the study with different design can provide rich data of the pro- and anti-vaccination. The data in this study can provide good information for the government and nurses in Indonesia to determine policies to increase vaccine coverage. The government knows that there are still many people with anti-vaccine. Poor understanding can increase the low coverage of vaccines in children. In addition, nurses with a good approach and can provide information about the importance of vaccines in children. Not only that, nurses, as providers of the basis for further policy determination, can work together with the government, as well as influencers in promoting the importance of the vaccine through mass and social media.

\section{Conclusion}

The purpose of this study was to explore the background and reasons for mothers deciding to 
become members of the anti-vaccine and pro-vaccine communities. This study is considered to have provided additional insights for health workers and the government to correct interventions that have been carried out to increase basic immunization standards coverage. The themes and categories obtained were identified through semi-structured interviews that could understand the current phenomena. The current literature focused on increasing the coverage of basic immunization without listening to the complaints and what barriers prevent mothers from immunizing their children. Further research can explore the parents' experiences whose children who became victims of AEFIs. The health workers are expected not underestimated and seemed to be irresponsible after administering immunizations.

\section{References}

1. Rémy V, Zöllner $Y$, Heckmann U. Vaccination: The cornerstone of an efficient healthcare system. J Mark Access Health Policy. 2015;1:1-6. https://doi.org/10.3402/jmahp.v3.27041

PMid:27123189

2. Ministry of Health of the Republic of Indonesia. Indonesian Health Profile for 2017. Jakarta: Ministry of Health of the Republic of Indonesia; 2018. https://doi.org/10.25133/jpssv27n1.003

3. Kusnanto $\mathrm{K}$, Arifin $\mathrm{H}$, Kurniawati $\mathrm{Y}$. Determinant of $\mathrm{BCG}$ vaccine coverage among Indonesian children aged 0-2 months. Child Youth Serv Rev. 2020;116:105238. https://doi.org/10.1016/j. childyouth.2020.105238

4. Mediarti D, Rosnani R, Sukartini T, Arifin H, Kurniawati $Y$. Coverage and factors associated with complete polio vaccination among Indonesian children aged 0-18 months. Child Youth Serv Rev. 2020;118:105399. https://doi.org/10.1016/j. childyouth.2020.105399

5. Stolle LB. Fact vs fallacy : The anti-vaccine discussion reloaded. Adv Ther. 2020;37(11):4481-90. PMid:32965654

6. World Health Organization. How to Respond to Vocal Vaccine Deniers in Public. Geneva: World Health Organization; 2017.

7. Sulistiawati D. Berikan Anak Imunisasi Rutin Lengkap, Ini Rinciannya, Republika; 2018. Available from: https:// www.republika.co.id/berita/gaya-hidup/info-sehat/18/04/30/ p7zgl4328-berikan-anak-imunisasi-rutin-lengkap-ini-rinciannya. https://doi.org/10.31227/osf.io/dyvmg

8. Sobo EJ. Theorizing (vaccine) refusal: Through the looking glass. Cultur Anthropol 2016;31(3):342-50. https://doi. org/10.14506/ca31.3.04

9. Ward PR, Attwell K, Meyer SB, Rokkas P, Leask J. Understanding the perceived logic of care by parents: A qualitative study in Australia. PLoS One. 2017;12(10):e0185955. https://doi. org/10.1371/journal.pone.0185955 PMid:29023499

10. Domek GJ, O'Leary ST, Bull S, Bronsert M, Contreras-Roldan IL, Ventura GA, et al. Measuring vaccine hesitancy: Field testing the WHO SAGE Working Group on Vaccine Hesitancy survey tool in Guatemala. Vaccine. 2018;36(35):5273-81. https://doi. org/10.1016/j.vaccine.2018.07.046

PMid:30061026

11. Creswell JW. Penelitian Kualitatif dan Desain Riset. Yogyakarta: Pustaka Pelajar; 2014.

12. World Health Organization. Vaccine Safety Communication 2018 Meeting Report. Geneva: World Health Organization; 2018. p. 31.

13. Gu Z, Badger P, Su J, Zhang E, Li X, Zhang L. A vaccine crisis in the era of social media. Natl Sci Rev. 2018;5:8-10.

14. McNeil DG. Religious Objections to the Measles Vaccine? Get the Shots, Faith Leaders Say. New York: The New York Times; 2019.

15. Hadisuyatmana S, Krisnana I, Sipahutar MA. Factors influencing mothers' intention to immunize children younger than five years of age in west borneo: A cross-sectional study. J Ners. 2019;14(1):41. https://doi.org/10.20473/jn.v13i2.9406

16. Wallace AS, Wannemuehler K, Bonsu G, Wardle M, Nyaku M, Amponsah-Achiano K, et al. Development of a valid and reliable scale to assess parents' beliefs and attitudes about childhood vaccines and their association with vaccination uptake and delay in Ghana. HHS Public Access. 2019;37(6):848-56. https:// doi.org/10.1016/j.vaccine.2018.12.055

PMid:30642731

17. Danchin M, Kaufman J. Building Vaccine Confidence: More Information is Not Enough, InSigh; 2019. Available from: $\quad$ https://www.insightplus.mja.com.au/2019/7/ building-vaccine-confidence-more-information-is-not-enough .

18. Bianco A, Mascaro V, Zucco R, Pavia M. Parent perspectives on childhood vaccination: How to deal with vaccine hesitancy and refusal? Parent perspectives on childhood vaccination : How to deal with vaccine hesitancy and refusal? Vaccine. 2019;37(7):984-90. https://doi.org/10.1016/j. vaccine.2018.12.062

PMid:30655175

19. Olorunsaiye $C Z$, Langhamer $M S$, Wallace $A$, Watkins $M L$. Missed opportunities and barriers for vaccination: A descriptive analysis of private and public health facilities in four African countries. Pan Afr Med J. 2017;27(Suppl 3):1-9. https://doi org/10.11604/pamj.supp.2017.27.3.12083

20. Panting AJ. Potential factors contributing to vaccine hesitancy among parents in malaysia: An overview. Int J Health Sci Res. 2018;8(7):360-5

21. Nadeem N. Spotlight: Paediatric vaccine preventable disease. Br J Fam Med. 2018; 6(5):1-6.

22. Burgess L. Debunking the Anti-vaccination Myths. Brighton: Medical News Today; 2019.

23. Ugezu C, Essajee M. Exploring patients awareness and healthcare professionals knowledge and attitude to pertussis and in $\mathrm{fl}$ uenza vaccination during the antenatal periods in Cavan Monaghan general hospital. Hum Vaccin Immunother. 2018:14(4):978-983. https://doi.org/10.1080/21645515.2017.14 19110

PMid:29257941

24. Dybsand LL, Hall KJ, Carson PJ. Immunization attitudes, opinions, and knowledge of healthcare professional students at two Midwestern universities in the United States. BMC Med Educ. 2019;19:242. https://doi.org/10.1186/s12909-019-1678-8 PMid:31266481 